\title{
ESTÉTICA Y POLÍTICA EN EL PERIODO CHILENO DE MARIANO PICÓN SALAS (1923-1935)
}

\author{
Ioannis Antzus Ramos \\ American University in Dubai, Emiratos Árabes Unidos \\ yananra@hotmail.com
}

\section{RESUMEN/ ABSTRACT}

En el presente artículo estudiamos la concepción estética y las relaciones entre estética y política en los ensayos de Mariano Picón Salas escritos en Chile entre 1923 y 1935. En sus textos sobre arte, el joven Picón Salas promovía obras armónicas y auténticas en que el significado y el significante así como el creador y el entorno establecerían una relación univoca. De manera paralela, en lo que concierne a la política, Picón quería crear un orden consensual en que las elites y el pueblo tendrían un vínculo necesario, lo que permitiría superar la crisis institucional y social, y emprender el camino de una modernización afín al modelo europeo.

Palabras clave: Mariano Picón Salas, literatura chilena, literatura venezolana, ensayo hispanoamericano.

\section{Aesthetics and politics Within the ChILEAN Period of Mariano Picón SALAS (1923-1935)}

In this article I study the aesthetic thought and the relations between aesthetics and politics in the essays that Mariano Picon Salas wrote in Chile between 1923 and 1935. In his texts on art, the young Picon Salas valued authentic and harmonious works in which the meaning and the signifier as well as the creator and the context established an unambiguous relation. At the same time, in what concerns his political thought, Picon longed for an agreement between the elites and the people that would lead to overcome the institutional and social crisis and to undertake the road of modernization.

KEYWords: Mariano Picon Salas, Chilean Literature, Venezuelan Literature, Spanish American Essay. 
Mariano Picón Salas (Venezuela, 1901-1965) emigró con su padre a Chile en 1923 debido a la ruina de la hacienda familiar y a la difícil situación política que se vivía en Venezuela bajo la dictadura de Juan Vicente Gómez (1909-1935). El ensayista residió allí durante doce años, y durante ese tiempo completó su formación académica, publicó sus primeros ensayos y novelas importantes, y participó activamente en la vida intelectual. Esta prolongada estadía en Chile dejó en él una huella indeleble y es evidente que influyó tanto en sus escritos publicados en ese momento como en toda su obra posterior. Sin embargo, este periodo de su obra ha pasado prácticamente desapercibido para la crítica. El objetivo del presente artículo es estudiar la concepción estética y las relaciones entre estética y política en el joven Picón Salas tomando en consideración sus ensayos escritos en Chile entre 1923 y 1935 . Para llevar a cabo nuestro propósito abordaremos, primeramente, la concepción estética del autor. En este sentido nos centraremos en su propuesta de establecer una síntesis armónica entre el fondo y la forma que permitiría a las obras del continente superar los excesos expresivos y operar el paso de lo particular a lo universal. A continuación veremos algunos ejemplos del ideal estético que él proponía -la Grecia clásica, Goethe-y, con base en este ideal, estudiaremos su concepción de la escritura. Por último, analizaremos la estrecha relación que se establece entre la concepción estética y los planteamientos políticos de Picón Salas, pues en ambos dominios el autor anhelaba la creación de un orden armónico y consensual.

\section{LA UNIÓN DEL FONDO Y DE LA FORMA}

En lo que concierne a la creación artística, el joven Mariano Picón Salas rechazaba a aquellos creadores que se alejaban de su contexto histórico,

\footnotetext{
Durante su estadía en Chile, Picón Salas publicó los siguientes libros: Mundo Imaginario (1927), "Hispanoamérica, Posición Crítica" (1931), Odisea de Tierra Firme (1931), "Problemas y Métodos de la Historia del Arte" (1933), Imágenes de Chile (Vida y costumbres chilenas en los siglos XVIII y XIX) (1933), Registro de Huéspedes (1934), e Intuición de Chile y otros Ensayos en Busca de una Conciencia Histórica (1935). Además, editó numerosos artículos en las revistas Atenea, Letras, Revista Chilena e Índice, muchos de los cuales fueron compilados por su hija en el valioso volumen Prosas sin finalidad (1923-1944). En el presente artículo nos referimos sobre todo a los ensayos recogidos en esta compilación y a los incluidos en Intuición de Chile.
} 
ya fuera en el tiempo -cuando se quedaban anclados en el pasado- o en el espacio -cuando imitaban, sin asimilar, lo que se producía en otros contextos. Él consideraba que las épocas de decadencia se caracterizaban por una desconexión entre las ideas y el medio que daba lugar a una retórica carente de contenido. Por eso, en un ensayo sobre historia del arte fechado en 1933, afirmaba que el ocaso del arte de la Antigüedad se hizo evidente "cuando el recargo y superabundancia de materiales $[. .$.$] destruye la unidad del conjunto.$ Lo accesorio predomina sobre lo principal. Una técnica, una retórica, una virtuosidad vacía se realiza con prescindencia del tema" ("Problemas..." 53). Picón Salas advertía precisamente que este síntoma de decadencia-el alejamiento de la realidad en favor de una forma abstracta- estaba muy presente en Hispanoamérica. Para el joven ensayista, el gran problema de la cultura del continente era que había sido imposible establecer una correspondencia armónica entre el sujeto y el objeto, entre las ideas y el medio, y entre la forma y el contenido. Para decirlo con sus palabras: "el lado más peligroso de nuestra acción y nuestro pensamiento criollo es el olvido de esa realidad concreta: cierto ofuscado "nominalismo" [...] que supone que basta el nombre y la palabra para crear la cosa. Así, nuestra cultura y nuestra política se colmaba de rótulos sin contenido" ("El intelectual..." 240). Al relegar la propia circunstancia, los hispanoamericanos habían creado obras retóricas y abstractas. Picón Salas consideraba que era preciso revertir esta situación $\mathrm{y}$ crear obras bien compensadas en que el fondo y la forma, y el artista y el medio establecieran una relación armónica y necesaria. Esta síntesis era el camino que él proponía para crear una estética auténtica e independiente que establecería al fin una relación horizontal con la de los países metropolitanos.

Picón Salas consideraba que la falta de autenticidad estética en el continente tenía su origen en la época de la Colonia. Siguiendo al historiador británico Henry T. Buckle², Picón pensaba que la Contrarreforma había supuesto para España un alejamiento de Europa y la había condenado a la contemplación del pasado. Al no ser capaz de ir con la hora que marcaba el reloj europeo y al rechazar las ideas que venían de fuera, el intelecto español se volvió sobre sí mismo dando lugar al "recargo formal -sin contenido- de los culteranos", a "la retórica inerte", y al "aplebeyamiento y vulgaridad de su siglo XVIII" (“La mentalidad..." 205). Esta mentalidad conservadora y antieuropea pasó

$2 \quad$ Nos referimos a Henry Thomas Buckle (1821-1862), quien trata sobre España en el capítulo XV de la Introducción a su History of Civilization in England (1857-1861). 
a América a través de la educación clerical, que estableció una gran distancia entre el pensamiento y la realidad:

No es la propia experiencia, la síntesis que el individuo pensante y responsable ha elaborado, la que lo guía en medio del caos de las cosas. Es un criterio infantil de autoridad: las farragosas citas que colman sus discursos, traídas sin mesura ni selección de los padres de la Iglesia; es la máquina alegórica, las metáforas y la mitología extraída de los libros de retórica, algo que se repite rutinaria y mecánicamente sin relación alguna con el individuo; es la artificiosa deducción que parte de lo más lejano para llegar al hecho próximo y simple ("La mentalidad..." 207).

Al negar la experiencia concreta, la Colonia fue sobre todo, en palabras de Picón Salas, una "edad retórica" ("La mentalidad..." 210), es decir, una época que disimulaba el pensamiento bajo el disfraz del verbalismo. El periodo colonial se caracterizó por la separación entre la palabra y la cosa, entre el ser americano y su propia experiencia. Por lo tanto, al encontrarse a sí mismos, al hallar lo que de verdad eran, los hispanoamericanos estarían en condiciones de alcanzar la verdadera independencia. Superar los excesos que tuvieron su origen durante la dominación española-todavía presentes en el continente- $\mathrm{y}$ hallar la expresión auténtica eran así para el joven ensayista dos caras de la misma moneda ${ }^{3}$.

Picón Salas pensaba que la desconexión entre el sujeto y el objeto y entre las ideas y el propio contexto era también evidente en dos movimientos estéticos de la época republicana, el Romanticismo (en su tendencia más superficial) y el arielismo, a los que criticó con dureza. En cuanto a la primera de estas corrientes, nuestro autor afirmaba que en su versión más epidérmica era una estética limitada por su falta de estructura, ya que en ella "el canon de la belleza" es "el corazón del artista". Lo que él rechazaba de la escuela romántica era que "no conoce la Historia en cuanto esta es voluntad, imposición,

3 Ortega y Gasset había culpado también a la Colonia de la falta de autenticidad del continente. Para el filósofo español la situación colonial suponía también una distancia entre las ideas y el medio, entre el hombre y la tierra: "la vida colonial no es la autóctona. Es decir, que el hombre que la vive no pertenece al espacio geográfico en que la vive". Por eso, para Ortega, "el colonial es siempre [...] un retroceso del hombre hacia su relativo primitivismo en cuanto afecta al fondo de su psique, pero conservando un outillage material y social -es decir, cuanto afecta al orden externo-de plena modernidad" (Meditación 166, 168). 
destino, y se queda en la biografía" ("Estética... 266). Picón pensaba que el arte debía ser algo más que un mero impulso o arranque súbito del alma: debía ser construcción y combinación de formas, esto es, debía proceder del acto consciente de ordenar y someter la materia ("Problemas...", 56). Los escritores románticos que él más estimaba eran precisamente aquellos cuya escritura no procedía exclusivamente del rapto o del instinto liberados, sino del control y la reflexión. Es decir, aquellos que habían escapado a la palabrería y a la vana retórica para ser capaces de ofrecer un testimonio de su paso por la historia. Por eso valoraba positivamente obras como el Facundo de Sarmiento, las Bases de Alberdi o la Mercurial Eclesiástica de Montalvo, ya que estas obras expresan, "cualesquiera que sean sus defectos de forma y lo eventual de sus ideas políticas, el testimonio candente del hombre ante la tierra"4 ("Prólogo..." 11).

Además de oponerse al Romanticismo más superficial, Picón Salas impugnaba a los escritores de la generación inmediatamente anterior a la suya, a la cabeza de los cuales situaba a José Enrique Rodó, autor del Ariel (1900). A juicio de nuestro ensayista, el excesivo énfasis formal del escritor uruguayo habría dado lugar a un estilo en que el significante y el significado no se correspondían:

El error y el olvido que ya cubre a algunos escritores de América, como Rodó, es que ganaron en forma lo que perdieron en vida y en pasión. Así sus escritos donde el arabesco disimula el contenido y lo redondo no deja ver el músculo, parecen dirigidos al auditorio vespertino y empaquetado de los Ateneos. Se parecen extrañamente a esos ejercicios de Retórica que eran obligado ornamento de la educación jesuítica ("Prólogo..." 11-12).

Como vemos, Rodó se habría preocupado excesivamente del estilo. Esto le habría llevado a crear obras superficialmente perfectas pero vacías de contenido, lo que le convertía en heredero de la tradición escolástica de la Colonia. Picón Salas pensaba que este intelectual y sus seguidores habían

$4 \quad$ Dentro de este grupo de autores del siglo XIX, Picón Salas también incluye a Bilbao (Chile) y a González Prada (Perú). 
cometido el error de buscar conscientemente la forma en lugar de crearla, lo que habría dado lugar a una literatura inarmónica e inauténtica ${ }^{5}$.

Frente a la desconexión entre el significante y el significado que advertía tanto en cierto romanticismo como en el arielismo, Picón reivindicaba a aquellos autores en los que apreciaba una consonancia entre la obra y la vida, y entre la vida y la historia. El ideal de completitud estética que él reclamaba suponía una continuidad perfecta entre el creador y la creación, así como una unidad entre el fondo y la forma que no dejara lugar a excesos de cosas o de palabras. Para él, los grandes creadores eran los que hacían posible la expresión propia al establecer un consenso entre su personalidad, la obra y el contexto que redundaba en una coincidencia precisa entre significante y el significado. Al hacerse uno con su destino y con su entorno, el artista hispanoamericano conseguiría superar también la imitación acrítica de los modelos extranjeros y estaría en condiciones de crear obras del mismo valor.

Al plantear este ideal estético, el joven Picón Salas se situaba en el espacio abierto en las letras hispanoamericanas por Pedro Henríquez Ureña y Alfonso Reyes. El intelectual dominicano, en su ensayo "El descontento y la promesa", de Seis ensayos en busca de nuestra expresión (1928), había llamado a la creación auténtica y había indicado que para lograr una expresión original no era necesario ceñirse a una imagen preestablecida de la propia realidad sino concentrarse en el trabajo. El esfuerzo sostenido daría como consecuencia el hallazgo de una coincidencia precisa entre el significante y el significado que acabaría con los excesos de cosas y de palabras que tanto daño habían hecho, según él, a la literatura hispanoamericana. Esto implicaba un rechazo del Romanticismo hispanoamericano más superficial, que para él estaba en el origen de la exuberancia expresiva y de la búsqueda obsesiva de la originalidad. Para Henríquez Ureña esta corriente estética se caracterizó porque en ella

nuestra literatura absorbió ávidamente agua de todos los ríos nativos: la naturaleza; la vida del campo, sedentaria o nómada; la tradición

\footnotetext{
Picón Salas proponía que no había que forzar la originalidad, sino que esta surgiría de la propia creación. En este sentido recuperaba la idea que ya había formulado Henríquez Ureña. Dice el dominicano: "No hay por qué apresurarnos a definir nuestro espíritu encerrándolo dentro de fórmulas estrechas y recetas de nacionalismo; bástenos la confianza de que existimos, a pesar de los maldicientes, y la fe de que llegaremos a fundar y a representar la libertad del espíritu" ("Caminos..." 56).
} 
indígena; los recuerdos de la época colonial; las hazañas de los libertadores; la agitación política del momento... La inundación romántica duró mucho, demasiado; como bajo pretexto de inspiración y espontaneidad protegió la pereza, ahogó muchos gérmenes que esperaba nutrir... ("El descontento..." 34).

Desde el punto de vista de Ureña, “cada gran manifestación estética debe crear su propia forma"; por eso, frente a lo grandilocuente y lo superficial proponía retornar "a un modo de expresión natural y justa" ("Rubén Darío" 300).

Alfonso Reyes, que en esta época ya mantenía correspondencia con Picón Salas ${ }^{6}$, defendía un ideal de autenticidad estética en términos semejantes a los de Henríquez Ureña. En su ensayo "Visión de Anáhuac" (1915) se aprecia un rechazo explícito a la concepción romántica y exotista de lo hispanoamericano. Dice allí que "la cantada selva virgen de América, apenas merece describirse" puesto que responde a una visión europea (es "tema obligado de admiración en el Viejo Mundo") e inspira el exceso de palabras ("los entusiasmos verbales de Chateaubriand") (5). A lo largo de su obra, el intelectual mexicano rechazó "la exuberancia verbal", pero también su contraparte, "la nebulosidad intelectual" y en relación con ello declaró, refiriéndose al continente, "el fárrago es lo que nos mata" (Gutiérrez Girardot, "Prólogo" XVII). Asimismo, al valorar la obra de uno de sus grandes maestros, Reyes estimaba precisamente la comunión adecuada en su escritura del fondo con la forma:

Una virtud suprema ilumina la obra histórica de Justo Sierra: la veracidad, la autenticidad mejor dicho. Todo en ella es auténtico, todo legítimo y sincero, resultado de una forma del alma, y no condición exterior y yuxtapuesta: sus directrices mentales [...]; su liberalismo [...]; sus desbordes de emoción que en otros resultarían inoportunos y aquí fluyen como al empuje de una verdadera necesidad; su expresión retórica, que en otros sonaría algo hueca y aquí aparece íntimamente soldada al giro de los pensamientos. Auténticas la intención, la idea, la palabra. Auténtico el desvelo patriótico que lo inspira ("Justo Sierra..."126).

Esta armonía de la letra con la idea suponía en el pensamiento de Reyes la coincidencia del sujeto y la expresión, valor que destacaba al hablar de

6 Las cartas entre ambos están recogidas en Gregory Zambrano (comp.): Odiseos sin reposo, México, UNAM, 2007. 
"la estética sincera" de Amado Nervo. Esta sinceridad se mostraba en el hecho de que la literatura y la vida establecían en la obra del vate mexicano una continuidad: "por cualquier página que lo abro, el libro me descubre al hombre" ("Tránsito..." 129).

Vemos así que tanto Reyes como Ureña hicieron de la síntesis y de la mesura su ideal estético y que rechazaron en consecuencia la inarmonía en el plano artístico. Hay que decir además que el pensamiento estético de ambos (así como también el de Picón Salas) hunde sus raíces en el romanticismo alemán y en el simbolismo francés. Ya Hegel en su Estética (1826) había concedido un peso fundamental al acuerdo entre la forma y la significación al indicar que "en la producción artística, la dimensión de lo espiritual y de lo sensible deben constituir una unidad" (41). Asimismo, la búsqueda de una armonía perfecta entre el significante y el significado había ocupado un lugar fundamental en la teoría poética simbolista, desde Baudelaire hasta Valéry. En estos poetas, como es bien sabido, la búsqueda de la expresión perfecta se convirtió en una obsesión y fue una reacción a la facilidad y a la improvisación que había traído consigo cierto Romanticismo.

\section{LO PARTICULAR Y LO UNIVERSAL}

En sus escritos de juventud, Picón Salas planteaba que cuando se establecía una síntesis armónica entre el artista, la obra y el contexto histórico, la creación estética operaba además el paso de lo particular a lo universal. Esto implica que para él, la poesía y el arte eran entidades transhistóricas que debían encontrar su materialización en cada circunstancia histórica concreta ${ }^{7}$. Para decirlo con sus palabras:

7 En este sentido es evidente su coincidencia con Reyes y Henríquez Ureña, pero también con Hegel y Keyserling. Para Hegel, el arte es transhistórico porque su función consiste en representar la idea: "el arte tiene la tarea de representar la idea para la intuición inmediata en forma sensible y no bajo la forma del pensamiento y de la espiritualidad pura. Y esta representación tiene su valor y dignidad en la correspondencia y unidad entre ambas partes, entre la idea y su forma. En consecuencia, la altura y excelencia del arte en la realidad correspondiente a su concepto dependerá del grado de interioridad y unidad en que la idea y la forma aparezcan elaborados en recíproca compenetración" (Estética 68). Además, la filosofía del sentido de Hermann von Keyseling habría tenido un hondo impacto en el joven Picón Salas. El filósofo báltico, siguiendo a Hegel, planteaba la necesidad de establecer una 
el concepto de poesía que aislemos en [La montaña mágica de] Tomás Mann no es sustancialmente distinto del que pudo ofrecernos Goethe, hace más de cien años. Como los versos de un Paul Valéry tampoco son formalmente diversos de los de Racine. Cambia el contenido, la materia que colma el vaso de la poesía; inscribe la época su signo particular, pero se mantiene lo universal del concepto ("Letra y espíritu...” 327. Cursiva nuestra).

Cuando arraiga en el medio histórico y en la persona del creador, la obra muestra un acuerdo entre la forma y el contenido que le permite revelar la verdad y lo esencial. Esto significa que toda poesía que resulte de una síntesis armónica en un contexto particular alcanza automáticamente la universalidad. Es por este motivo que para nuestro autor no tenía ningún valor la proliferación de "capillas esotéricas" en la época de la vanguardia, pues para él la meta del arte era la revelación de la verdad y de lo universal a partir de lo particular. En el texto titulado "Poesía, truco, subconsciencia", Picón Salas se oponía a las escuelas vanguardistas, señalando lo siguiente al respecto:

el problema de la poesía en este tiempo en que vivimos, es que ya ella no se resigna a su magnífico nombre sustantivo, sino adjetivamente, llamándose "poesía nueva", "superrealista", etc., trata de distinguirse y de excluir a las otras poesías, a las otras doncellas que pudieran ser sus rivales. No es que precisamente haya muerto la poesía en nuestra mecánica civilización, sino que ella se diluye, atomiza y disgrega en muchas formas y manifestaciones de la cultura y el arte de hoy (327).

Para Picón Salas, el intento de estas corrientes de "reservar para sí la exclusiva administración de las musas" estaba abocado al fracaso, pues la poesía y también, por extensión, el arte eran para él esencias eternas que debían simplemente actualizarse en cada época histórica concreta.

La idea de que una expresión estética armónica y adecuada conllevaba el paso de lo local a lo universal implica que Picón Salas no concebía la particularidad hispanoamericana en términos absolutos. En efecto, al igual

concordancia entre el fondo y la forma: "la expresión será más o menos adecuada [en la medida en que] la coordinación de sentido que representa el medio de expresión armonice con lo que se ha de expresar". Añadía además que "cuando se quiere expresar adecuadamente algo que se piensa no se trata propiamente de materializar algo espiritual, sino de establecer una relación orgánica necesaria entre lo pensado y los sentidos propios del medio de expresión" (82). 
que Alfonso Reyes y Pedro Henríquez Ureña, Picón Salas pensaba que el continente carecía de formas culturales propias, puesto que formaba parte del marco común de la cultura occidental. Por lo tanto, al solicitar el arraigo de las creaciones continentales en el propio contexto no estaba abogando por la mímesis de lo extranjero, pero tampoco por un ultranacionalismo cultural. Lo que Picón buscaba era un término medio entre las posturas americanistas y las extranjerizantes. Como vemos, también aquí la virtud se hallaba en la síntesis de los opuestos:

Negando lo propio, sometiéndonos indolentemente a nuestro carácter de factorías de la cultura europea, no afirmaremos nunca nuestra autonomía espiritual. [...] Pero hay que defenderse también de la sobrestima y el nacionalismo rabioso que nos cantan una canción optimista y nos ungen ya de un destino mesiánico. El optimismo sin crítica y la boba confianza no constituyen filosofía. [...] Lo que urge es, pues, no crear un método americano que no podría ser sustancialmente distinto del método europeo, ya que fuimos países de conquista y estamos en la ruta de la civilización occidental, sino cargar ese método de nuestra propia sustancia, hacerlo nuestro expresando nuestro contenido. Método europeo, contenido americano parece por el momento la fórmula conciliadora de nuestro supranacionalismo cultural ("Realismo..." 152-153).

Para nuestro ensayista, los conceptos y las formas literarias y artísticas habían sido creados ya por la tradición europea. Por lo tanto, los creadores hispanoamericanos debían conseguir que estas formas descargasen su energía al ponerlas en contacto con la "realidad próxima y vital" ("Símbolos..." 360). Al lograr la síntesis de la forma y del contenido, del sujeto y el objeto, y de la cultura con la vida, las obras hispanoamericanas trascenderían su situación particular y hablarían universalmente a todos los hombres.

\section{ÉPOCAS E INDIVIDUOS MODÉLICOS}

A la vez que planteaba este ideal estético, Picón Salas ponía ejemplos de momentos históricos y personalidades que lo alcanzaron. Entre las primeras, se refería sobre todo a la Grecia clásica (aunque también estimaba el 
Renacimiento italiano ${ }^{8}$ ) y en cuanto a los segundos, a Johann W. von Goethe y a Alfonso Reyes.

En el arte ateniense del siglo $\mathrm{V}$ a.C., nuestro autor advertía la unión perfecta del fondo con la forma y de las partes con el todo que constituía su ideal estético. Siguiendo a Hegel, Picón pensaba que la maravilla del arte griego era el resultado de la perfección del cuerpo social, puesto que en la Atenas de Pericles se había dado una "armonía entre Estado y región" y entre "individuo y sociedad" ("Un tema típico..." 72). Es evidente que el arte de la época clásica, en cuanto que era un modelo de perfección estética que se correspondía con una sociedad igualmente armónica, constituía para Picón Salas un motivo de nostalgia:

Fidias, Policleto, Praxíteles, Escopas, Lisipo: nunca la plástica fue más segura de su materia. Cada uno de esos nombres encierra para nosotros todo un mundo de imágenes corpóreas. Es la más maravillosa visión del cuerpo humano que haya hasta ahora conocido la historia de la cultura. En nuestras civilizaciones cansadas, resuena de pronto ese júbilo de la corporeidad griega, el escorzo del atleta, el pliegue flotante de la Niké que vuela, como un ideal irretornable ("Un tema típico..."75. Cursiva nuestra).

8 Es evidente que ya en esta época, Picón Salas, a raíz de la lectura de Burckhardt, estimaba el orden estético y social del Renacimiento italiano. En esta cita se ve un cierto lamento por la falta de arraigo del Renacimiento en la América colonial, donde se impusieron los estilos medieval y barroco, incapaces de síntesis: "El Renacimiento y su clara preceptiva formal, apenas rozaron la superficie del alma española. [...] Comparado con el racionalismo renacentista el barroco es intuición, contenido más que forma. Ello expresa mejor el "pathos" hispánico; por eso el espíritu español pasa de lo medioeval a lo barroco haciendo apenas el tránsito por un Renacimiento convencional y académico, extraño a su alma. En la América colonial no tuvimos, siquiera, esa transitoria etapa renacentista, y los hombres rudos y devotos que fundaron las primeras ciudades, dijeras que habían traído de España la ya fugitiva Edad Media. Luego veremos cómo la misma condición de la tierra no hizo sino arraigar más este medioevalismo" ("Mirando..." 101).

Este respeto por el ideal griego, Picón Salas lo compartía con Henríquez Ureña y Alfonso Reyes, pero también con Burckhardt y con Hegel. En "La cultura de las humanidades" (1914), Ureña ha explicado cómo su generación llevó a cabo un retorno a Grecia para distanciarse del positivismo imperante en la educación superior del porfiriato, y allí señala que "el milagro helénico" fue sin duda un modelo para su grupo intelectual. ("La cultura..." 60.) Por su parte, Alfonso Reyes tomó de los griegos clásicos su visión universal del hombre: “Al colar por el tamiz de la razón el espectáculo del universo, el griego -primero entre 
A pesar de la estima que mostraba por el arte clásico, Picón Salas era perfectamente consciente de que este paradigma estético no podía resurgir en los mismos términos. Contra lo que pensaban en el siglo XVIII Lessing o Wincklemann, nuestro ensayista no creía que el gran arte tuviera que ser una imitación del modelo natural llevado a la cima por el arte helénico. Dicho de otra forma, él no echaba de menos el arte clásico en sí mismo, sino el modelo de completitud que este arte representaba. Se pensaba entonces que este ideal era transhistórico y que a él debían tender todos los pueblos desde su situación particular ${ }^{10}$. Picón Salas quería recuperar la unión armónica del fondo y de la forma que advertía en el arte clásico, pero no con la lógica

todos los pueblos- lo concibe como una estructura de conjunto, como un organismo sujeto a leyes universales. E interpreta su deber terrestre como una investigación de esas leyes, para aplicarlas a la conducta humana y dar así al hombre su verdadero lugar en la naturaleza" ("De cómo Grecia..." 24). Esta concepción ecuménica del ser humano supone que este requiere adaptarse permanentemente, desde la propia circunstancia, a un ideal que es al mismo tiempo ético y estético. Reyes consideraba que valores griegos como la sophorosyne, el aidós, o la homonoia eran universales y fundaba en ellos su concepción moral, cultural y artística. En el ámbito europeo, la visión de lo griego que Picón Salas ya había aparecido antes en Hegel, para quien el mundo griego revelaba una eticidad perfecta: "la reunión de lo moral y de la voluntad subjetiva es tal, que la idea se encuentra unida a una figura plástica: no está en uno de los lados, por sí sola, abstracta, sino que está enlazada inmediatamente con lo real: al modo como en una obra de arte bella, lo sensible sustenta el sello y la expresión de lo espiritual" (Lecciones 206). Este consenso ideal entre el individuo y la colectividad de la época de Pericles dio lugar a un ideal estético que se revelaba en la escultura clásica. En ella, nos dice Hegel, "el interior espiritual [...] inhabita en la forma sensible y en su material exterior, de modo que ambas dimensiones se acuñan la una en la otra sin predominar ninguna" (Estética 78). Siguiendo a Hegel, Burckhardt había estimado el ideal de la época clásica griega (y el del Renacimiento italiano) en que se daba una armonía cultural entre el fondo y la forma que revelaba la perfección del cuerpo social.

10 A este respecto, nuestro autor coincidía con las ideas que, siguiendo a Hegel y a Spengler, había propuesto el Conde de Keyserling para superar la decadencia europea. En su obra El conocimiento creador (1922), el fundador de la Escuela de Sabiduría había afirmado que era necesario establecer las condiciones para que el espíritu encarnase de nuevo en la historia. Para este pensador, el ideal de un pueblo se materializaba cuando era capaz de establecer una armonía entre su propio ser y el sentido que se manifestaba en el momento histórico. Los pueblos, dice Keyserling, “aparecen grandes únicamente cuando encarnan un espíritu de verdadero valor, es decir, cuando representan un símbolo. Pero esto sólo ocurre en el caso de que el sentido y la expresión se correspondan exactamente, y, por tanto, en el caso de un pueblo, cuando el espíritu eterno penetre completamente la totalidad de su carácter especifico. La experiencia enseña que de nada aprovecha tomar o representar un espíritu ajeno por perfecto que sea" (72. Cursiva nuestra). 
del siglo V a.C. (lo que supondría negar la historia), sino con la lógica del presente que él vivía. Su intención era fundar una "buena" modernidad o una modernidad "clásica" (valga la paradoja), es decir, un tiempo que siendo actual permitiera también la síntesis del sujeto y del objeto, y que diera lugar a un arte igualmente armónico que documentase la salud del cuerpo social.

Picón Salas aclaraba esta cuestión al reflexionar sobre la crítica de arte. Para él, esta no podía ser dogmática - es decir, no podía remitir la obra a un ideal atemporal como querían los pensadores neoclásicos- sino que debía ser morfológica, esto es, debía tratar de comprender la obra en relación con su propia época histórica:

El arte es una forma social como la religión, como el lenguaje. Hay que estudiarlo morfológicamente. Y el arte surge así no como el "arquetipo" divino y absoluto, sino como una conquista del hombre contra la irrealidad de las cosas. Al mundo inseguro de la Naturaleza el hombre opone el mundo espiritual del Arte. Más que la belleza al modo antiguo, interesa a la actual Ciencia del Arte la significación. Lo que el hombre quería representar: lo que dentro de su voluntad étnica e histórica podía representar. En cada forma se plasma un contenido. Y la nueva estética no aplicará a las obras de arte la escuadra con que los arqueólogos del Renacimiento medían las estatuas antiguas, sino - problema mucho más importante- buscará la relación entre esa forma y ese contenido. En esto, y no en la "proporción" griega, ni en la "anatomía" renacentista, estriba su matemática ("Estética..."266).

La crítica de arte y de literatura tenía entonces que buscar la correspondencia entre la forma y el contenido, es decir, tenía que "aplicar a los productos de cada época artística la propia ley de su querer y su propia imagen del mundo" ("Capacidad..." 269), pues solo así conseguiría revelar "la actitud espiritual de una época ante el mundo" ("Literatura..." 136). Como decía el ensayista en otro texto de juventud: "Lo que importa es buscar en cada ciclo cultural, en cada estilo, las leyes de su propio querer representativo. Lo que nos sirvió para entender lo griego no lo aplicaremos a lo gótico. Una ley universal no se aplica al fenómeno, sino cada fenómeno crea su ley particular" ("Problemas..." 50).

Asimismo, Picón veía cumplido en autores como Goethe o Reyes el modelo de orden estético que él planteaba. Lo que más estimaba Picón Salas del gran escritor alemán era su capacidad para superar con éxito la gran crisis que advino con la llegada de la modernidad. Más en concreto, nuestro autor 
destacaba que Goethe fue un autor que no concibió el clasicismo como un acontecimiento histórico pasado sino como una actitud que se podía y se debía rescatar desde el presente. "Sólo Goethe opone a ese patetismo agotador de los comienzos del siglo XIX la salud de la forma clásica, del Clasicismo no como lo explican los Manuales de Literatura, ni como lo esquematizó el siglo XVIII, sino como surge de su paisaje meridional, cuando junto al mar de Sicilia [...] la Odisea se le convirtió en palabra viva" ("Presencia..." 173). Lo clásico significaba entonces la presencia de lo universal y de lo verdadero y, por tanto, era un ideal atemporal que podía reivindicarse en cualquier momento. Fue gracias a este ideal que Goethe, a diferencia de sus contemporáneos, no se dejó llevar por el "individualismo disgregador" que advino a finales del siglo XVIII. En cambio, el escritor alemán templó el desasosiego que trajeron consigo los nuevos tiempos recurriendo a la forma clásica y a la conciliación de los excesos:

Nuestro espíritu occidental nutrido de lo pagano y lo cristiano, del Norte y del Mediodía, no ha podido conciliar este tremendo dualismo de alma y cuerpo, contenido y forma, cultura y naturaleza, que es el drama del primer Fausto. Junto al claro contorno y a la limitación griega, el occidental opone su trágico deseo de infinitud. En Goethe desembocan y se encauzan como en ningún hombre moderno, estas corrientes divergentes de la historia universal. Él acerca Fidias a Rembrandt. Ofrece a la desesperanza occidental, a nuestro contenido turbulento, la blanca hospedería acogedora de la forma clásica ("Presencia..." 173).

Goethe fue un modelo para Picón Salas en la medida en que recurrió a "lo natural" y a "lo objetivo", es decir, a lo universal, para salvar el "frenes'́, que advino con la llegada de la modernidad. Él logró, como dice nuestro autor, reconciliar en su voluntad vital "lo moderno y lo antiguo, lo clásico y lo romántico", y por eso todavía "el espíritu moderno acude a Weimar a pedirle al olímpico consejero, su mensaje de integradora unidad" ("Presencia..." 173). En sus grandes obras literarias, a través de un detenido esfuerzo sobre la forma que le permitió disciplinar el instinto, el autor del Fausto alcanzó lo universal. Este mismo ideal ecuménico era el que Picón Salas quería para el arte y la literatura de Hispanoamérica. Era necesario trabajar la forma y lograr la conciliación de los contrarios para crear así obras mesuradas y sin excesos, locales y globales al mismo tiempo, que serían una muestra de que 
en el continente hispanoamericano era posible alcanzar una modernidad armónica, similar a la de las naciones europeas.

Entre los autores del continente, nuestro autor destacaba que la escritura (y la personalidad) de Alfonso Reyes lograba esta anhelada síntesis de los opuestos. En el ensayo "Un testimonio de Alfonso Reyes", Picón Salas indicaba que este intelectual se caracterizaba por "una comprensión que sabe situarse en la frontera precisa de lo racional y lo afectivo" y señalaba también, a propósito de la obra El testimonio de Juan Peña (1930) que "este hermoso libro, como todos los del maestro mexicano, guarda en la disciplina gozosa de su estilo un denso contenido espiritual". Al conciliar adecuadamente lo instintivo y lo racional, Reyes debía ser un modelo para los escritores del continente: "nuestras literaturas delirantes, de instinto informe, con las lianas colgantes de la improvisación y el «dejar hacer", encuentran en escritores como Reyes el imperativo ético: la clara ordenación de la inteligencia" ("Un testimonio..." 122, 125).

\section{LA ESCRITURA MESURADA}

Las ideas estéticas de Picón Salas tuvieron consecuencias asimismo en su concepción de la escritura. En el pensamiento de nuestro autor, el arte y la palabra eran documentos que inscribían en su propio cuerpo la armonía (o desarmonía) del cuerpo social. Por eso, si el arte debía ser un modelo de orden donde lo afectivo y lo racional se reconciliaban para hallar la verdad y lo universal, el lenguaje escrito debía igualmente huir de los excesos y revelar una síntesis armónica. Ya hemos visto cómo por herencia de la educación escolástica colonial los letrados hispanoamericanos se habían olvidado de la realidad próxima y concreta. Este distanciamiento habría dado lugar a la "imaginación verbalista", vicio continental por excelencia al que Picón Salas se refería también con el término "tropicalismo", una suerte de enfermedad que presentaba los siguientes síntomas:

Adjetivos que no convienen al concepto, palabras esdrújulas que suelen llenar grandes huecos del pensamiento, repeticiones, hipérboles, tono sostenidamente patético, son los elementos del cuadro clínico de nuestro verbalismo escrito. Y todo ello se resuelve en el pensamiento y en la vida por la actitud espiritual que en estas tierras australes se suele llamar "tropicalismo". "Tropicalismo" es incapacidad de 
llamar las cosas por su justo nombre, delirio verbal, deformación de los hechos o las ideas (“América..." 107).

Como se ve por la cita, el exceso de retórica a la hora de escribir encubría defectos más profundos en el ámbito del pensamiento y de la lógica. Era necesario, por tanto, que a través de la educación, los hispanoamericanos pusiesen orden en sus ideas, ya que ese orden se traduciría en una escritura más mesurada y plena de contenido:

esto de escribir con claridad y sentido de las proporciones, es también un problema de educación. Se escribe confusamente cuando se piensa con obscuridad y hay que rellenar con palabras gordas el teatro vacío de las ideas. La lógica, la sencilla y usual lógica, es la mejor agua regia contra la retórica. Y la síntesis y la concisión sólo pueden darse en mentes trabajadas por el estudio, el orden intelectual y la responsabilidad creadora (“América..." 108).

Vemos así que también en el ámbito de la expresión escrita había que hallar la "mesura" y el "comedimiento". Para ello era necesario extender a través de la educación una "deferencia por las ideas y por la lógica" que permitiera dar a las palabras su justo sentido. Al dar al significado su valor, se equilibraría la tendencia continental al formalismo y a la grandilocuencia, y se cumpliría, también en este campo, el acceso a una modernidad ordenada. Según dice expresamente el propio Picón Salas en referencia a una serie de críticas literarias cargadas de retórica que habían aparecido en la prensa:

Estas "trompas broncíneas" [la cita corresponde a una de esas críticas], o mejor de caña hueca, son las que ahogan toda voz de cultura moderna que quiera levantarse en Hispano-América. Es ya hora de reaccionar contra el tropicalismo. Conocemos el fenómeno y la manera de desviarlo. Mientras en nuestro continente se piensa, se escriba y se obre de esta manera -porque el verbalismo contagia también la acción y la vida-seremos pueblos inferiores ("América..." 112. Cursiva nuestra).

Para ser pueblos modernos y "superiores" era preciso rechazar la palabrería, ya que ella encubría el retraso de los hispanoamericanos en el pensar y en el obrar. Había que establecer de una vez por todas la síntesis armónica entre las ideas y la realidad, entre el sujeto y el objeto, y entre la forma y el contenido para que así la escritura, el arte y, en general, la cultura del 
continente alcanzasen la ansiada universalidad y coincidiesen, desde su propia particularidad, con los cánones que nuestro autor advertía en las grandes obras y momentos de la cultura occidental. Para conseguir este objetivo, es decir, para modernizar adecuadamente la cultura del continente era necesario extender la educación a las masas. Así, en última instancia, la solución a los excesos éticos y estéticos de los hispanoamericanos pasaba por la creación de un nuevo tipo de hombre, es decir, por la conversión del otro popular en un ciudadano afín al modelo político y estético que él estaba promoviendo ${ }^{11}$.

\section{ESTÉTICA Y POLÍTICA}

La reflexión sobre la estética que aparece en los escritos juveniles de Mariano Picón Salas guarda una estrecha correspondencia con sus planteamientos sobre el rumbo que debía seguir la política del continente. El propio Picón Salas se daba cuenta de la relación tan cercana que se establece entre todos los órdenes de una realidad histórica y, particularmente, llamaba la atención sobre el vínculo entre la política y la estética. En ese sentido afirmaba, por ejemplo, que

[1]a temperatura de fe es la que demanda toda creación trascendente; ella se necesita para fundir las imágenes de una obra de Arte y para juntar en la más complicada obra que es un Estado, en la alegría y la disciplina de una vasta Historia nacional, el grupo humano contradictorio. Los pueblos como los hijos, brotan de las cálidas entrañas (“Intuición...”235).

Para Picón, entonces, se requería una misma voluntad para dar forma a esos dominios interrelacionados que son el arte y el Estado. En otro texto de esta época indicaba igualmente que sus opiniones acerca de la literatura se

11 Que todo se reducía a esta estrategia biopolítica se aprecia bien en este comentario de Mariano Picón Salas a Rómulo Betancourt en una carta fechada en 1931 y en referencia a Venezuela. Dice Picón Salas: "HAY QUE CREAR ALLÁ UN NUEVO TIPO DE HOMBRE. El morenito romántico con música de Andrés Mata y de Santaella, lunático y bebedor de caña, es un ser sin defensa alguna contra el imperialismo". (Cit. en J. M. Siso Martínez, Mariano 168. Mayúscula del original). En otra carta dirigida a Betancourt en abril de 1932, Picón afirmaba igualmente: "Nuestro problema es hacer un país moderno de esa tierra de doctorcitos, malos poetas e historiadores epopéyicos” (Cit. en J. M. Siso Martínez, Mariano 179). 
podían trasladar fácilmente a otros campos de la realidad. Por eso, después de expresar su punto de vista sobre cuál debía ser la relación de la literatura hispanoamericana con la europea, señalaba lo siguiente: "con las palabras anteriores expresé lo que pensaba del nacionalismo en literatura. Pudiera extenderlas a otras formas de la realidad como la economía o la política"12 ("Realismo..." 153). Vemos así que nuestro ensayista no separaba su reflexión sobre el arte de su planteamiento sobre el mundo común y que en ambos dominios estableció un mismo "reparto de lo sensible" (Rancière, El reparto 10). En verdad, como lo ha indicado Jacques Rancière, ambas esferas son inseparables, porque es imposible pensar en un orden para el arte que sea autónomo y que no implique al mismo tiempo un orden para la realidad, y viceversa ("Las paradojas..." 67). Política y estética son dos caras de la misma moneda, y esta coincidencia entre ambos dominios se aprecia con mucha claridad en los ensayos chilenos de nuestro autor.

En el momento en que Picón Salas escribía los planteamientos sobre estética que hemos analizado más arriba, Chile se encontraba inmerso en un proceso de cambio de régimen. En efecto, la nación austral estaba sufriendo en estos años un "proceso de reacomodo social", pues en ella se estaba fraguando un nuevo "equilibrio de poder en la fase de aparición de nuevos sectores sociales" (Campos 58). En el primer cuarto del siglo $\mathrm{XX}$ se había hecho evidente que el régimen parlamentario, dirigido por la oligarquía, no podía dar respuestas a los conflictos que amenazaban a la sociedad chilena. Esto motivó constantes huelgas y movilizaciones que se canalizaron inicialmente con las esperanzas puestas en el primer gobierno de Arturo Alessandri (1920-1925). Sin embargo, pronto se hizo evidente que la transformación del viejo sistema político en uno nuevo no dependía solo de un cambio de gobierno.

La obra chilena de Picón Salas se escribió en un contexto histórico en que era necesario inventar una nueva forma de concebir la política y la sociedad. Más en concreto, el pensamiento de nuestro autor durante este lapso formó parte del intento de las nuevas clases medias chilenas por construir una hegemonía cultural (Gramsci, "Análisis..." 414) alternativa a la de la oligarquía. El objetivo de estas clases en ascenso era imponer al

12 Picón Salas compartía una concepción morfológica de la historia con Burckhardt, Spengler, Keyserling y Waldo Frank. Todos ellos concebían la historia como una estructura en que las diferentes partes establecían entre sí relaciones de correspondencia. 
resto de la sociedad su cosmovisión para así naturalizar su propio liderazgo. En un proceso que había ido ganando peso desde principios del siglo XX, los intelectuales pertenecientes a estos grupos se consideraron a sí mismos los "auténticos intérpretes de la nacionalidad" (Barr-Melej 3. Traducción nuestra) y, a través de la escritura literaria y de la educación pública, trataron de imponer su proyecto de reforma de la política y de la sociedad. Nuestro autor actuó como un "intelectual orgánico" (Gramsci, "La formación..." 388) de estos colectivos sociales en ascenso, y contribuyó con su escritura a este proyecto político-cultural estrechamente vinculado al proceso de modernización capitalista del país.

Ante la situación de crisis política y social que se vivía en el Chile de los años veinte y treinta del siglo pasado, Picón Salas se concibió a sí mismo como el constructor de un nuevo orden ${ }^{13}$. Desde su punto de vista, la desconexión entre las clases altas y la propia realidad estaba en el origen de los problemas que impedían el desarrollo del país y del continente. Por eso, Picón se propuso restablecer el vínculo social en base a una definición más amplia de lo nacional y articular, en base a esa identidad incluyente, un proyecto político y cultural de largo alcance. Esto suponía incorporar las grandes masas al Estado y dirigir convenientemente esta incorporación para dar lugar a la creación de Estados modernos no fallidos. Frente al descuido con que las oligarquías habían tratado al pueblo, nuestro autor sabía que ya era imposible construir cualquier programa político o cultural sin contar con él.

Además de la necesidad de representar políticamente a las masas, Picón consideraba imprescindible establecer una síntesis entre los diferentes grupos sociales y entre las diversas posiciones políticas. Su ideal por eso era el término medio frente a los extremismos políticos y sociales y así como rechazaba una sociedad polarizada entre las élites y el pueblo, se apartaba de cualquier posición radical. Por eso indicaba que frente a las posturas del

13 En este sentido, los modelos predilectos de Picón Salas eran San Agustín y Goethe. Sobre el primero de ellos decía: “Acaso el ejemplo más revelador, y para mí casi monstruoso, del papel del intelectual en la discordia de los hombres, es el [...] de San Agustín, que cuando veía morir la cultura antigua, trazaba el cuadro de un nuevo orden espiritual, esa esperanza en medio de la desolación colectiva que se llamó la «Ciudad de Dios"”. ("El intelectual..."115). Por su parte, el escritor alemán, cuya obra estaba siendo reivindicada en ese momento por intelectuales como Henríquez Ureña y Alfonso Reyes, era también un ejemplo para nuestro autor en la medida en que consiguió minimizar en su obra y en su pensamiento el impacto que supuso la llegada de la modernidad a principios del siglo XIX ("Presencia..." 93). 
reaccionario y del revolucionario, él prefería "la coyuntura de una tercera y más justa posición, la del que busca una perspectiva y anhela extraer del fugitivo instante la más permanente enseñanza" ("El intelectual..." 115). En base a este término medio que para él era sinónimo de lo verdadero y de lo universal, Picón Salas pensaba que era preciso articular una identidad cultural que animase el presente y anticipase el porvenir. Por eso, si bien reconocía la necesidad de reformar las leyes sociales y el nivel económico, para él lo prioritario era crear un orden cultural que hiciera a los países hispanoamericanos dueños de su propio destino y les permitiera convertirse en Estados modernos y soberanos.

Esta concepción política implicaba que Picón Salas quería construir en América Latina una modernidad ordenada, semejante a la que imaginaba en las naciones europeas. En base a una interpretación occidentalista y superficial de la modernidad, el joven Picón intentaba corregir los excesos y las disonancias que la realidad hispanoamericana presentaba con relación al Viejo Continente. Desde su punto de vista, los países europeos eran modelos de orden y completitud, pues en ellos se cumplían las dos condiciones que él creía necesarias para construir una modernidad adecuada: por un lado, la síntesis de los opuestos, es decir, la conciliación de las élites y el pueblo, de la pasión y de la inteligencia; por el otro, la relación de continuidad entre la tradición y el progreso, entre el ser y el estar ${ }^{14}$. En sus ensayos de la época chilena, Picón Salas anhelaba implantar en Chile y, por extensión, en Hispanoamérica, este modelo de orden que para él era universalmente válido. En el mundo perfecto que él anhelaba las élites y el pueblo estarían unidos y la nación sería una con el Estado de manera que no habría agentes en exceso al cuerpo social. Lo que así estaba reclamando Picón Salas era una suerte de clasicismo moderno: un orden armónico y consensual en que no hubiera elementos sobre-numerarios que amenazasen la estabilidad del sistema.

Vemos entonces que para Picón Salas tanto el mundo común como la obra de arte debían ser modelos de completitud en que las partes se correspondieran

14 "[Ser y estar] son los dos primeros verbos históricos. Y en la tensión del ser y la fijeza del estar (la fuerza del cambio y la fuerza de la tradición), se sitúa la cultura. La cultura equilibra, pues, las fuerzas externas de cambio o transformación (en la técnica, en la economía, en la vida política) con la personalidad permanente que se revuelve en el fondo del ser histórico. Este equilibrio cultural es el que nos falta. Nuestras crisis de política y de educación son crisis de formas que pugnan por adaptarse a una realidad en que no se ven soldadas ni correspondidas" (Picón Salas, "Literatura..." 149). 
con el todo y en que no hubiera elementos de más que amenazasen la armonía del conjunto. La política y el arte, como dos partes complementarias de un mismo proyecto, debían conciliar las diferencias y los excesos inherentes a toda realidad social y a toda creación estética. El pensamiento del joven Picón Salas buscaba fundar así un nuevo orden de lo sensible que, basado en una supuesta homogeneidad de las naciones metropolitanas, reduciría la multiplicidad de los países hispanoamericanos y permitiría sentar las bases de un proyecto de nación fundado en valores considerados universales. El arte que acompañaría a este nuevo modelo de nación debía reproducir esta misma homogeneidad de manera que las creaciones artísticas revelaran una identidad entre el fondo y la forma y entre el artista y el medio que pondría en valor la universalidad (y por tanto, la mayoría de edad) del continente hispanoamericano.

Ahora bien, este ordenamiento de lo sensible hace visibles varias contradicciones del pensamiento juvenil de Picón Salas, muchas de las cuales perdurarán en su obra de madurez. Al buscar una modernidad "adecuada" en el ámbito de la política, el joven ensayista estaba negando la noción misma de ruptura que define la modernidad en favor de un orden consensual en que el sujeto y el objeto coincidirían. Igualmente, al proponer como ideal artístico la creación de obras cerradas y perfectas en que la forma y el fondo encajarían perfectamente, Picón estaba rechazando los excesos de cosas y de palabras que desde finales del siglo XVIII definen el concepto mismo de la modernidad literaria (Rancière, La palabra muda...). Esto sucedió porque Picón Salas estaba pensando el continente hispanoamericano (y el modelo europeo) a partir de las ideas de Pedro Henríquez Ureña y de Alfonso Reyes que -herederos en este sentido del arielismo- habían pretendido transformar América Latina en base a una utopía atemporal fundada por el pensamiento griego (Gutiérrez Girardot, "Pedro..." y "Prólogo"). Hay que decir además que tanto Picón Salas como Reyes y Ureña fueron sensibles a las ideas de tres pensadores que en esta época estaban desarrollando una crítica conservadora de la modernidad. En un contexto de reflexión sobre la profunda crisis de valores que vivía Occidente, Oswald Spengler, Hermann von Keyserling y Waldo Frank culparon a la modernidad y a la cultura de masas de la decadencia y buscaron restituir un cosmos pre-moderno libre de excesos, en que el ser y el estar, el logos y el eros, y el hombre y la colectividad pudieran reestablecer una existencia armónica. Impregnado de este clima de época, Picón Salas trató de conciliar las disonancias éticas y estéticas del continente en base a una concepción antimoderna. Corregir los excesos de 
Hispanoamérica implicaba superar las profusiones de la modernidad e imponer una cultura firme y estable en que el sujeto y el objeto y el significante y el significado establecerían al fin una continuidad armónica. El joven ensayista planteó así un modelo político y estético aparentemente perfecto que, sin embargo, cancelaba la historia y negaba el impulso crítico y progresivo de la modernidad. Pensamos por eso que el pensamiento del joven Picón Salas revela la actitud característica de los procesos democratizadores que se han dado en Hispanoamérica desde la Independencia. En ellos, si por un lado se percibe una voluntad de ofrecer una definición de lo nacional acorde con los valores en que se apoyan los grupos dirigentes en ascenso, por otro -en una "sutil compensación"- se fortalecen los principios que van a legitimar el poder político y cultural de estos colectivos (Rama 134). Al tratar de imponer un modelo político y estético "universalmente válido", Picón estaba en verdad reduciendo la complejidad de Chile y del continente hispanoamericano en favor de un ideal de uniformidad que, al basarse en un modelo de estado liberal y occidentalista, facilitaba y normalizaba el ascenso al poder de las nuevas clases medias.

En suma, convencido de que el momento histórico exigía un reemplazo de las clases dominantes y un nuevo proyecto para la vida en común, el joven Picón Salas dedicó sus esfuerzos a plantear en su escritura un ideal político y estético coherente que, nacido en estrecho contacto con la convulsa realidad chilena de los años veinte y treinta, tendrá también un gran peso en el diseño de la Venezuela del siglo XX.

\section{BIBLIOGRAFÍA}

Barr-Melej, Patrick. Reforming Chile. Cultural Politics, Nationalism and the Rise of the Middle Class. The University of North Carolina Press, 2001.

Campos, Miguel Ángel. "Mariano Picón Salas y el petróleo recelado". Vigencia de Mariano Picón Salas. Mérida: Casa Nacional de las Letras Andrés Bello, 2001. 11-65.

Gramsci, Antonio. “Análisis de las situaciones. Correlaciones de fuerzas”. Antología. Buenos Aires: Siglo XXI Editores, 2004. 412-416.

"La formación de los intelectuales". Antología. Buenos Aires: Siglo XXI Editores, 2004. 384-389.

Gutiérrez Girardot, Rafael. "Pedro Henríquez Ureña”. En Pedro Henríquez Ureña, La utopía de América. Caracas: Biblioteca Ayacucho, 1979. IX-XXXVI. IX-XLII.

“Prólogo”. En Alfonso Reyes, Última Tule. Caracas: Biblioteca Ayacucho, 1991. 
Hegel, Georg W. F. Estética. Tomo 1. Barcelona: Ediciones Península, 1989.

Lecciones sobre la filosofia de la historia universal. Madrid: Alianza Editorial, 2004.

Henríquez Ureña, Pedro. "Caminos de nuestra América”. La utopía de América. Caracas: Biblioteca Ayacucho, 1979. 47-56.

"El descontento y la promesa". La utopía de América. Caracas: Biblioteca Ayacucho, 1979. 34-45.

"La América española y su originalidad". La utopía de América. Caracas: Biblioteca Ayacucho, 1979. 24-27.

"La cultura de las humanidades". La utopía de América. Caracas: Biblioteca Ayacucho, 1979. 47-56.

"Rubén Darío". La utopía de América. Caracas: Biblioteca Ayacucho, 1979. 300-305.

Keyserling, Hermann von. El conocimiento creador. Madrid: Espasa Calpe, 1930.

Ortega y Gasset, José. Meditación del pueblo joven y otros ensayos sobre América. Madrid: Alianza Editorial, 1981.

Picón Salas, Mariano. “América y el disparate”. Intuición de Chile. Santiago de Chile: Nascimento, 1935. 107-112.

"Capacidad y voluntad artística”. Prosas sin finalidad. Caracas: Universidad Católica Andrés Bello, 2010. 268-269.

"El intelectual y la humana discordia". Prosas sin finalidad. Caracas: Universidad Católica Andrés Bello, 2010. 236-240.

"Estética dogmática y estética morfológica". Prosas sin finalidad. Caracas: Universidad Católica Andrés Bello, 2010. 266-267.

"Intuición de Chile". Prosas sin finalidad. Caracas: Universidad Católica Andrés Bello, 2010. 228-235.

"La mentalidad colonial". Prosas sin finalidad. Caracas: Universidad Católica Andrés Bello, 2010. 205-214.

"Letra y espíritu: vida y doctrinarismo". Prosas sin finalidad. Caracas: Universidad Católica Andrés Bello, 2010. 336-337.

"Literatura y actitud americana". Intuición de Chile. Santiago: Nascimento, 1935.137-138.

"Mirando unos primitivos americanos: pintores de El Cuzco". Intuición de Chile. Santiago de Chile: Nascimento, 1935. 101-106.

"Nuevas notas sobre un viejo tema histórico. La caída de Roma y la civilización antigua". Prosas sin finalidad. Caracas: Universidad Católica Andrés Bello, 2010. 76-89.

"Poesía, Truco y Subconsciencia". Prosas sin finalidad. Caracas: Universidad Católica Andrés Bello, 2010. 327-330.

"Presencia de Goethe". Prosas sin finalidad. Caracas: Universidad Católica Andrés Bello, 2010. 173-174.

"Problemas y métodos de la Historia del Arte". Las formas y las visiones. Caracas: Universidad Católica Andrés Bello, 2007. 46-60. 
"Prólogo y digresiones sobre América". Intuición de Chile. Santiago de Chile: Nascimento, 1935. 9-12.

"Realismo y cultura en Hispanoamérica". Prosas sin finalidad. Caracas: Universidad Católica Andrés Bello, 2010. 141-154.

"Símbolos y murallas". Prosas sin finalidad. Caracas: Universidad Católica Andrés Bello, 2010. 360-361.

"Un tema típico de Historia del Arte. La escultura griega". Las formas y las visiones.

Caracas: Universidad Católica Andrés Bello, 2007. 61-75.

"Un testimonio de Alfonso Reyes". Intuición de Chile. Santiago de Chile: Nascimento, 1935. 121-125.

Rama, Ángel. La ciudad letrada. Madrid: Lineo, 2010.

Rancière, Jacques. El reparto de lo sensible. Estética y política. Santiago: Lom, 2009.

La palabra muda. Ensayo sobre las contradicciones de la literatura. Buenos Aires:

Eterna Cadencia, 2009.

"Las paradojas del arte político". El espectador emancipado. Pontevedra: Ellago ediciones, 2010. 60-84.

Reyes, Alfonso. "De cómo Grecia construyó al hombre". Última Tule. Caracas: Biblioteca Ayacucho, 1991. 23-45.

"Justo Sierra y la historia patria". Última Tule. Caracas: Biblioteca Ayacucho, 1991. 120-126.

128-135.

“Tránsito de Amado Nervo". Última Tule. Caracas: Biblioteca Ayacucho, 1991.

"Visión de Anáhuac". Última Tule. Caracas: Biblioteca Ayacucho, 1991. 5-16.

Siso Martínez, J. M. y Juan Oropesa. Mariano Picón Salas. Caracas: Fundación Diego Cisneros, 1978.

Zambrano, Gregory (comp.). Odiseos sin reposo. México: UNAM, 2007. 